\title{
The association of betaine, homocysteine and related metabolites with cognitive function in Dutch elderly people
}

\author{
Simone J. P. M. Eussen ${ }^{1}$, Per M. Ueland ${ }^{2}$, Robert Clarke ${ }^{3}$, Henk J. Blom ${ }^{4}$, Willibrord H. L. Hoefnagels ${ }^{5}$, \\ Wija A. van Staveren ${ }^{1}$ and Lisette C. P. G. M. de Groot ${ }^{1}$ \\ ${ }^{1}$ Division of Human Nutrition, Wageningen University, P.O. Box 81296700 EV Wageningen, The Netherlands \\ ${ }^{2}$ Section for Pharmacology, Institute of Medicine, University of Bergen and Haukeland University Hospital, Armauer Hanssen Hus \\ (Building), 5021 Bergen, Norway \\ ${ }^{3}$ Clinical Trial Service Unit and Epidemiological Studies Unit, University of Oxford, Oxford OX3 7LF, UK \\ ${ }^{4}$ Department of Clinical Chemistry, VU University Medical Center, PO Box 70571007 MB Amsterdam, The Netherlands \\ ${ }^{5}$ Department of Geriatrics, University Medical Center Nijmegen, PO Box 91016500 HB Nijmegen, The Netherlands
}

(Received 14 August 2006 - Revised 29 March 2007 - Accepted 3 April 2007)

\begin{abstract}
The importance of the one-carbon metabolites, choline and homocysteine, to brain function is well known. However, the associations between the one-carbon metabolites choline, betaine, methionine and dimethylglycine with cognition in elderly are unclear. We therefore examined the associations of these metabolites with cognition in a double-blind, placebo-controlled trial. Individuals ( $n$ 195) were randomized to receive daily oral capsules with either $1000 \mu \mathrm{g}$ cobalamin (vitamin $\mathrm{B}_{12}$ ), or $1000 \mu \mathrm{g}$ cobalamin plus $400 \mu \mathrm{g}$ folic acid, or placebo for 24 weeks. Concentrations of homocysteine, methionine, choline, betaine and dimethylglycine were assessed before and after 12 and 24 weeks of treatment. Cognitive function, including domains of attention, construction, sensomotor speed, memory and executive function, was assessed before and after 24 weeks of treatment. At baseline, elevated plasma homocysteine was associated with lower performance of attention, construction, sensomotor speed and executive function. In addition, betaine was positively associated with better performance of construction, sensomotor speed and executive function, whereas elevated concentrations of methionine were positively associated with sensomotor speed. Daily combined supplementation with cobalamin plus folic acid decreased total homocysteine concentrations by $36 \%$, and increased betaine concentrations by $38 \%$. Participants with the largest increases in betaine concentrations showed a borderline significant $(P=0 \cdot 07)$ higher memory performance compared to those without it. Although this trial observed associations of homocysteine and betaine with cognitive domains prior to supplementation, decreased concentrations of homocysteine were not related to improved cognitive performance. There was a tendency of participants with the largest increases in betaine concentrations to show the greatest improvement in memory function.
\end{abstract}

Elderly: Homocysteine: Choline: Betaine: Dimethylglycine: Cognition

Elucidation of the risk factors for cognitive decline is required to prevent and possibly reverse age-related cognitive impairment in elderly people. In this respect, the one-carbon metabolism is of interest because plasma concentrations of homocysteine and related B-vitamins have been associated with cognitive impairment ${ }^{1-6}$. Moreover, choline plays an important role in normal brain development, in particular for memory and learning ${ }^{7}$.

The metabolites of the one-carbon metabolism are closely interrelated ${ }^{8,9}$. Homocysteine is located at a critical metabolic branch point with ramification to methyl- and sulphur group metabolism (Fig. 1). Homocysteine is formed from the essential amino acid methionine. Methionine is activated by its conversion to $S$-adenosylmethionine, and $S$-adenosylmethionine is required for methylation of many acceptor substrates, such as DNA, RNA, lipids, proteins, phosphatidylethanolamine, creatine, myelin basic protein and neurotransmitters ${ }^{10}$.
Methylation of, for example, phosphatidylethanolamine to form phosphatidylcholine, is important to maintain myelin sheaths of nerve tissue and thereby for central nervous system structure and function ${ }^{7}$. Homocysteine is remethylated to methionine by the cobalamin (vitamin $\mathrm{B}_{12}$ )-dependent enzyme, methionine synthase, which uses 5-methyltetrahydrofolate as a methyl donor. Deficiencies of folate and cobalamin impair this conversion and result in increased homocysteine concentrations ${ }^{11}$. In a few tissues, predominantly the liver and kidneys, homocysteine remethylation is also catalysed by the enzyme betaine-homocysteine methyltransferase. Methionine and dimethylglycine (DMG) are the products of this reaction. The methyl donor, betaine, is formed from choline, which also is a precursor for the neurotransmitter acetylcholine ${ }^{12}$. Conceivably, impaired one-carbon metabolism may be associated with cognitive impairment by affecting neurotransmitter metabolism and central nervous system function. 


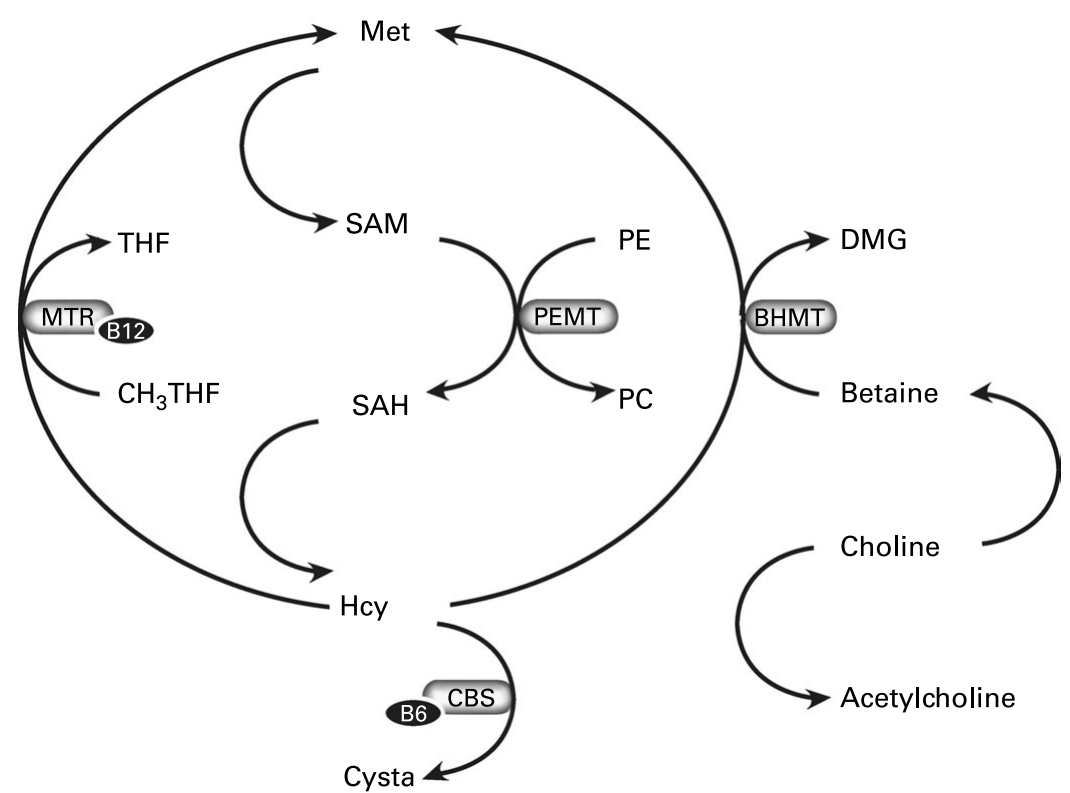

Fig. 1. $B$-vitamins $\left(B_{6}\right.$ and $\left.B_{12}\right)$, homocysteine $(\mathrm{Hcy})$, choline, betaine and the one-carbon metabolism. The conversion from Hcy to methionine (Met) can be catalysed by methionine synthase (MS) and betaine-homocysteine methyltransferase (BHMT). The conversion via MS requires cobalamin and 5-methyltetrahydrofolate (THF) as a methyl donor and couples folate metabolism to the choline-betaine pathway. Choline is provided by food or can be formed de novo via sequential $\mathrm{S}$-adenosylmethionine (SAM)-dependent methylation of phosphatidylethanolamine (PE) to form phosphatidylcholine (PC) by phosphatidylethanolamine $\mathrm{N}$-methyltransferase (PEMT). Choline is a precursor for the neurotransmitter acetylcholine or it is oxidized to betaine. Betaine donates its methyl group directly to homocysteine for the conversion into methionine, and results in dimethylglycine (DMG) in the BHMT reaction. CBS, cystathionine- $\beta$-synthase; $\mathrm{CH}_{3} \mathrm{THF}$, methyltetrahydrofolate; cysta, cystathionine; MTR, methionine synthase; SAH, S-adenosylhomocysteine.

Following the epidemiological associations found between homocysteine, cobalamin and folate with cognitive performance ${ }^{1-6}$, recent intervention trials investigated the efficacy of homocysteine lowering with B-vitamin supplementation on cognitive function in elderly people ${ }^{13-15}$. However, the associations of plasma concentrations of choline, betaine, DMG and methionine with cognitive performance have not been explored yet. A recently conducted efficacy trial, investigating the efficacy of oral cobalamin with or without folic acid supplementation on cognitive function ${ }^{14}$, provided such an opportunity. In addition, we assessed whether supplementation with cobalamin and folic acid altered plasma concentrations of choline, betaine and DMG, and consequently, whether alterations in these metabolites were associated with improvements in cognitive function.

\section{Subjects and methods}

\section{Participants}

Elderly men and women aged 70 years or older were screened for participation in a randomized double-blind placebo-controlled trial that studied the efficacy of oral cobalamin supplementation on cognitive performance ${ }^{14}$. Individuals were included when they had mild cobalamin deficiency, defined as serum cobalamin concentrations between 100 and $300 \mathrm{pmol} / 1$ in combination with plasma methylmalonic acid concentrations $\geq 0.32 \mu \mathrm{mol} / 1$ and serum creatinine concentration $\leq 120 \mu \mathrm{mol} / \mathrm{l}$ to exclude severe impairment of renal function ${ }^{16}$. Other exclusion criteria were history of cobalamin deficiency, use of cobalamin $(>50 \mu \mathrm{g} / \mathrm{d})$ or folic acid $(>200 \mu \mathrm{g} / \mathrm{d})$ supplementation or injections, surgery or diseases of the stomach or small intestine, anaemia, life-threatening diseases, severe hearing or visual problems, and severe cognitive impairment, which was defined by a score $<19$ points on the Mini-Mental State Examination (MMSE). An additional sample of individuals with adequate cobalamin status and no severe cognitive impairment ( $n$ 40) was enrolled for cross-sectional data analysis. Figure 2 presents the recruitment procedure, study design and flow of participants. The Medical Ethical Committee of Wageningen University approved the study protocol. Daily boards and client councils gave their consent for those individuals living in an institution, and written informed consent from all participants was obtained before the start of the study.

\section{Study design of the intervention trial}

Individuals who were included in the intervention trial started with a 2-week placebo run-in period prior to randomization. Within this period, individuals were excluded from further participation if compliance (intake of capsules) was $<90 \%$, or if they scored $<19$ points on the MMSE. Eligible participants were randomized to receive 24 weeks of treatment in a parallel group design with daily oral doses of $1000 \mu \mathrm{g}$ cobalamin, a combination of $1000 \mu \mathrm{g}$ cobalamin and $400 \mu \mathrm{g}$ folic acid, or a placebo capsule. Randomization was stratified according to methylmalonic acid concentration at the screening visit (below and above $0.45 \mu \mathrm{mol} / \mathrm{l}$ ), age (below and above 80 years), sex and MMSE (below and above 24 points).

\section{Blood collection and biochemical analyses}

A blood sample was collected at the screening and baseline visit and after 12 and 24 weeks of supplementation. A blood 


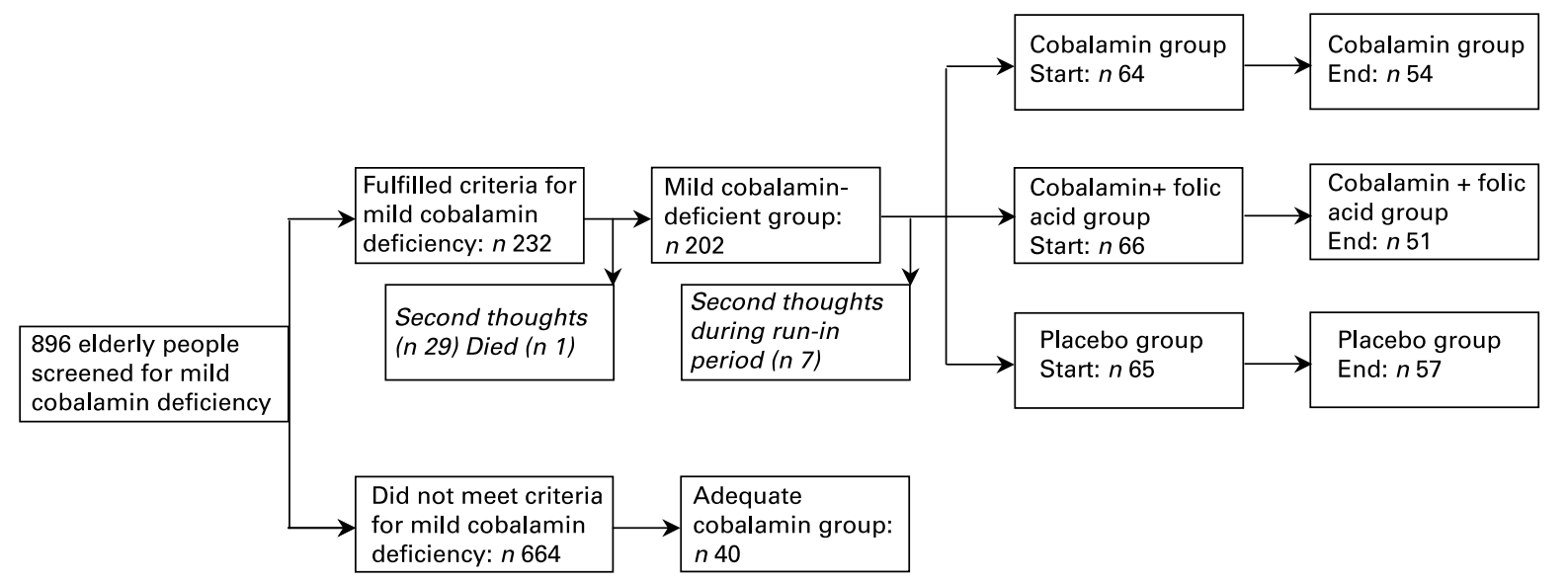

Fig. 2. Recruitment procedure, study design and flow of Dutch elderly participants.

Effects of intervention on one-carbon metabolites, and effect of metabolites on cognitive performance

sample for measurement of methionine, total homocysteine (tHcy), choline, betaine and DMG was collected into a $10 \mathrm{ml}$ Vacutainer ${ }^{\circledR}$ tube containing EDTA. This blood sample was placed in ice-water and centrifuged at $2600 \mathrm{rpm}$ for $10 \mathrm{~min}$ at a temperature of $4^{\circ} \mathrm{C}$ within $30 \mathrm{~min}$ of collection. All plasma samples were stored at $-80^{\circ} \mathrm{C}$ prior to laboratory analyses. Plasma concentrations were determined by a method based on methylchloroformate derivatization and GC-MS (methionine and $\mathrm{tHcy}^{17}$ and a modification of a method based on liquid chromatography tandem MS (choline, betaine and $\mathrm{DMG})^{18}$. Analytical $\mathrm{CV}$ of the assays for methionine, tHcy, choline, betaine and DMG were $<3 \cdot 4,<2 \cdot 2,<10$, $<10$ and $<10 \%$, respectively ${ }^{17,18}$.

\section{Assessment of cognitive function}

Six trained and registered neuropsychologists performed cognitive testing of the participants during a $1 \cdot 5-2 \mathrm{~h}$ session during the run-in period and at week 24 of intervention. The cognitive test battery consisted of tests that have been shown sensitive to the effects of B-vitamin treatment and ageing in previous studies ${ }^{2,19}$. Individuals were screened by the MMSE, and those with an MMSE score <19 points (maximum 30 points) were excluded because of severe cognitive impairment ${ }^{20}$. Table 1 lists the order of assessment and description of the tests, including its corresponding cognitive domain and neuropsychological focus. All these single tests were clustered into domains of attention, construction, sensomotor speed, memory and executive function, as indicated in the statistical methods. Three out of five domains were assessed by at least two tests that measured different aspects and/or degrees of complexities, which has been proposed as the preferred method for cognitive testing ${ }^{21}$. The advantages of clustered scores are (1) the reduction of measurement errors by possible floor and ceiling effects from difficult and easy tests, respectively; (2) to be able to account for missing data; (3) data reduction and thereby reducing chance findings; and finally (4) a better sensitivity to measure cognitive changes $^{21,22}$.

\section{Statistical methods}

The average concentrations of the biochemical parameters at the screening and randomization visits were calculated for each individual, and defined as 'baseline' concentrations. Differences in concentrations of blood parameters at baseline and follow-up were assessed with a two-factor repeated measures ANOVA (two measurements $\times$ three treatment groups) that included the time $\times$ treatment interaction. Tukey post hoc tests were used to assess differences between the intervention groups.

Data on cognitive function were presented as the neuropsychological domains of attention, construction, sensomotor speed, memory and executive function. The domains of attention and construction were assessed by a single cognitive test, while the other domains were assessed by multiple tests. All crude test scores were transformed to $z$-scores by: $z$ score $=(($ individual result - mean result of study population at baseline)/standard deviation of study population at baseline). The multiple tests for the domains of sensomotor speed, memory and executive function were clustered to provide compound $z$-scores to reduce the effects of chance findings and to simplify interpretation of the cognitive data: Attention $=Z_{\text {Digit }}$ Span Forward ; Construction $=Z_{\text {Rey,copy }}$; Sensomotor speed $=\left(-Z_{\text {Motor Planning (2) }}+-Z_{\text {Finger Tapping }}+-\right.$ $\left.Z_{\text {Trail Making (part A) }}\right) / 3$; Memory $=\left(Z_{15}\right.$ Word Learning, immediate $+Z_{15}$ Word Learning, delayed $+Z_{15}$ Word Learning, recognition $+Z_{\text {Rey, }}$ immediate $+Z_{\text {Rey, }}$ delayed $+Z_{\text {DigitSpan }}$ Backward $) / 6$; Executive function $=\left(-Z_{\text {Motor }}\right.$ Planning (3) $+-Z_{\text {Trail }}$ Making $\quad$ (partC/ partA) $+-Z_{\text {Stroop }}$ (part3/part2) $+Z_{\text {Similarities }}$ (WAIS) $+Z_{\text {Raven }}+$ $Z_{\text {Word Fluency (Animals) }}+Z_{\text {Word Fluency (Letter) }) / 7 \text {. }}$

Tests that were clustered for each cognitive domain were highly correlated $(\mathrm{P}$ values ranged from $<0.0001$ to 0.04 for all tests). Some participants were unable to complete all tests because of performance difficulties, e.g. tiredness. Compound z-scores were calculated when data for at least two, four and five tests for the domains of sensomotor speed, memory and executive function, respectively, were available. The compound $\mathrm{z}$-scores served as 'internal' $\mathrm{z}$-scores from 
WS British Journal of Nutrition

Table 1. Description of neuropsychological test battery with corresponding domain and neuropsychological focus

\begin{tabular}{|c|c|c|c|c|}
\hline Task and reference* ${ }^{*}$ & Domain & Neuropsychological focus & Description & Baseline score \\
\hline MMSE $^{34}$ & All & Global cognitive function & $\begin{array}{l}\text { Screening tool. Exclusion from further participation } \\
\text { if score }<19 \text { points at first visit }\end{array}$ & $27 \pm 3$ points (max. 30$)$ \\
\hline $\begin{array}{l}\text { Finger Tapping, } \\
\text { computerized }^{35}\end{array}$ & Sensomotoric speed & Simple sensomotor speed & Press a single button as often as possible within $30 \mathrm{~s}$ & $442 \pm 247 \mathrm{~ms}$ to press a button \\
\hline $\begin{array}{l}\text { Motor Planning_2, } \\
\text { computerized }^{35}\end{array}$ & Sensomotoric speed & Simple visuomotor reaction & $\begin{array}{l}\text { Press a lit button out of three buttons as quickly as } \\
\text { possible }\end{array}$ & $665 \pm 344 \mathrm{~ms}$ to press a button \\
\hline $\begin{array}{l}\text { Motor Planning_3, } \\
\text { computerized }^{35}\end{array}$ & Executive function & $\begin{array}{l}\text { Complex visuomotor } \\
\text { reaction }\end{array}$ & $\begin{array}{l}\text { Inhibit automatic reaction in pressing a button } \\
\text { immediately adjacent to a lit button as } \\
\text { quickly as possible }\end{array}$ & $1015 \pm 503 \mathrm{~ms}$ to press a button \\
\hline Figure of Rey - copy $^{36}$ & Construction & Visuoconstruction & Copy the complex figure of Rey from an example & $28 \pm 8$ points (max. 36$)$ \\
\hline $\begin{array}{l}\text { Figure of Rey - } \\
\text { immediate recall }^{36}\end{array}$ & Memory & Visual immediate memory & $\begin{array}{l}\text { Draw the complex figure of Rey without the example } \\
\text { immediately after the copy }\end{array}$ & $10 \pm 7$ points (max. 36$)$ \\
\hline $\begin{array}{l}15 \text { Word Learning - } \\
\text { immediate recall }^{37}\end{array}$ & Memory & Verbal immediate memory & $\begin{array}{l}\text { Read fifteen words five times and recall words in } \\
\text { between reading }\end{array}$ & $30 \pm 11$ correct words recalled \\
\hline Trail Making $A^{38}$ & Sensomotoric speed & Visuomotor speed & $\begin{array}{l}\text { Connect randomly placed numbers with a line as } \\
\text { fast as possible }\end{array}$ & $77 \pm 43$ s to complete task \\
\hline Trail Making $\mathrm{B}^{38}$ & Executive function & Concept shifting & $\begin{array}{l}\text { Connect randomly placed numbers and letters } \\
\text { alternated with a line as fast as possible }\end{array}$ & $207 \pm 141$ s to complete task \\
\hline Digit Span Forward ${ }^{39}$ & Attention & Attention & Repeat a string of digits in original order & $7.5 \pm 1.7(\max .16)$ \\
\hline Digit Span Backward ${ }^{39}$ & Memory & Working memory & Repeat a string of digits in reverse order & $4.9 \pm 1.7(\max .14)$ \\
\hline Raven $^{40}$ & Executive function & Visual reasoning & Choose a design that fits into a matrix & $15.4 \pm 3.9(\max .24)$ \\
\hline Stroop ${ }^{41,42}$ & Executive function & Interference & $\begin{array}{l}\text { Name colour of the ink while inhibiting the automatic } \\
\text { response of reading rather than the word (part } 3 \text { ). } \\
\text { Part 1: reading names of colours red, green, yellow, } \\
\text { blue; part 2: naming coloured blocks red, green, } \\
\text { yellow, blue }\end{array}$ & $\begin{array}{l}\text { Part 1: } 0.61 \pm 0.21 \text { false } \\
\text { Part 2: } 1.37 \pm 0.68 \text { false } \\
\text { Part 3: } 5.97 \pm 3.45 \text { false } \\
\text { answers }\end{array}$ \\
\hline $\begin{array}{l}\text { Figure of Rey - } \\
\text { delayed recall }^{36}\end{array}$ & Memory & Visual delayed memory & $\begin{array}{l}\text { Draw the complex figure of Rey without the } \\
\text { example } 30 \text { min after seeing the copy }\end{array}$ & $9.7 \pm 6.9(\max .36)$ \\
\hline $\begin{array}{l}15 \text { Word Learning - } \\
\text { delayed recall }^{37}\end{array}$ & Memory & Verbal delayed memory & Recall the words of the fifteen word learning test & $4.8 \pm 3.5(\max .15)$ \\
\hline $\begin{array}{l}15 \text { Word Learning - } \\
\text { recognition }{ }^{37}\end{array}$ & Memory & Consolidation & Recognize the original fifteen words, of thirty words read & $25.8 \pm 3.9(\max .30)$ \\
\hline Similarities (WAIS) ${ }^{43}$ & Executive function & Verbal reasoning & Mention similarities between five pairs of nouns & $4.9 \pm 2.9(\max .12)$ \\
\hline Verbal Fluency, letter ${ }^{44}$ & Executive function & Word generation & $\begin{array}{l}\text { List as many nouns beginning with letter } P \\
\text { ( } 0 \text { weeks) or } G \text { ( } 24 \text { weeks) as possible in } 2 \text { min }\end{array}$ & $15.4 \pm 6.9$ nouns listed \\
\hline Verbal Fluency, animal ${ }^{44}$ & Executive function & Word generation & List as many animals as possible in $1 \mathrm{~min}$ & $17.5 \pm 5.7$ animals listed \\
\hline GDS $^{45}$ & Emotional status & Depression & Self-rating scale for depression & $2.9 \pm 2.9(\max .15)$ \\
\hline
\end{tabular}

GDS, Geriatric Depression Scale; MMSE, Mini-Mental State Examination.

*Ordered by assessment. 
which $\mathrm{Z}$-scores at baseline and 24 weeks by study treatment were derived.

Baseline information of the present study population with mild cobalamin deficiency combined with an additional group of elderly with adequate cobalamin status enabled us to explore associations between the one-carbon metabolites and cognitive performance by means of partial correlation coefficients which were corrected for age and education.

Per protocol analyses were performed, including only the 162 participants $(84 \%)$ who completed the trial. Changes in cognitive performance associated with alterations of metabolite concentration were calculated by subtracting $z$-scores at the end of the intervention study by the $z$-scores at baseline. The potential effects of changes in metabolites on cognitive function within each domain within and across tertile categories in biochemical changes were studied by a two-factor repeated measures analyses (two measurements $\times$ three tertile categories) for each cognitive domain that included the time $\times$ tertile category interaction term. These analyses were performed with mixed models (SAS PROC MIXED procedure ${ }^{23}$ ), an extension from the linear regression model that includes random effects. Possible inter-investigator bias of the six neuropsychologists was entered as random effects. Statistical analyses were conducted using SAS statistical software version 9.1 (SAS Institute Inc., Cary, NC, USA).

\section{Results}

\section{Characteristics of participants}

Cross-sectional analyses have been performed for 202 elderly with mild cobalamin deficiency and forty elderly with adequate cobalamin status. The mean age of these participants was 81 (SD 6) years, $74 \%$ of the participants were females, and $40 \%$ of the participants lived in a care facility home. The mean score on the MMSE was 27 (SD 3) points which indicates that most of the population had intact cognitive function or only mild impairment.

The demographic, lifestyle and co-morbidity characteristics of participants are presented in Table 2. Although there were some differences with respect to lifestyle, medical history and mental status between those with mild cobalamin deficiency and those with adequate cobalamin status, there were no differences between those with mild cobalamin deficiency and the total population used for cross-sectional analyses (Table 2). Of the individuals with mild cobalamin deficiency who started with the run-in period ( $n$ 202), seven showed second thoughts, resulting in 195 participants who underwent random assignment. Two of these 195 participants dropped out during the run-in period, which left data for 193 participants who started supplementation (Fig. 2).

Table 2. Characteristics of older participants

\begin{tabular}{|c|c|c|c|}
\hline & $\begin{array}{c}\text { Mild cobalamin } \\
\text { deficiency }(n \text { 202; } \\
\text { intervention study) }\end{array}$ & $\begin{array}{c}\text { Adequate } \\
\text { cobalamin } \\
\text { status }(n 40)\end{array}$ & $\begin{array}{c}\text { Total population } \\
\text { cross sectional } \\
\text { analyses ( } n \text { 242) }\end{array}$ \\
\hline \multicolumn{4}{|l|}{ Demography } \\
\hline Age, mean (SD) years $\dagger$ & $82 \pm 5$ & $79 \pm 6$ & $81 \pm 6$ \\
\hline Sex, male, $n(\%) \ddagger$ & $50(25)$ & $13(33)$ & $63(26)$ \\
\hline Living, institutionalized, $n(\%) \ddagger$ & $90(45)$ & $6(15)$ & $96(40)$ \\
\hline \multicolumn{4}{|l|}{ Education level, $n(\%)$} \\
\hline Low $\ddagger$ & $80(40)$ & $4(10)$ & $84(35)$ \\
\hline Middle & $92(45)$ & $17(43)$ & $109(45)$ \\
\hline High $\ddagger$ & $30(15)$ & $19(47)$ & $49(20)$ \\
\hline \multicolumn{4}{|l|}{ Lifestyle $n(\%)$} \\
\hline Ex-Smokers $\ddagger$ & $63(31)$ & $3(8)$ & $66(27)$ \\
\hline Smokers & $18(9)$ & $2(5)$ & $20(8)$ \\
\hline Social drinking, $n(\%) \ddagger$ & $85(42)$ & $8(20)$ & $93(38)$ \\
\hline Vegetarian, $n(\%) \ddagger$ & $10(5)$ & $0(0)$ & $10(4)$ \\
\hline Multivitamin use, $n(\%) \ddagger$ & $39(19)$ & $3(8)$ & $42(17)$ \\
\hline \multicolumn{4}{|l|}{ Medical history } \\
\hline Myocardial infarction, $n(\%) \ddagger$ & $30(15)$ & (0) & $30(12)$ \\
\hline Stroke, $n(\%) \ddagger$ & $10(5)$ & (0) & $10(4)$ \\
\hline Transient ischaemic attack, $n(\%) \ddagger$ & $3(19)$ & $1(3)$ & $40(17)$ \\
\hline Angina pectoris, $n(\%) \ddagger$ & $34(17)$ & $4(10)$ & $38(16)$ \\
\hline Diabetes mellitus, $n(\%)$ & $19(9)$ & $3(8)$ & $22(9)$ \\
\hline Hypertension, $n(\%) \ddagger$ & $56(27)$ & $4(10)$ & $60(25)$ \\
\hline $\mathrm{H}_{2}$ antagonist/proton pump inhibitors, $n(\%) \ddagger$ & $49(24)$ & $1(3)$ & $50(21)$ \\
\hline \multicolumn{4}{|l|}{ Neurological symptoms } \\
\hline MMSE, mean (SD) pointsł & $26 \cdot 6 \pm 3.2$ & $28.9 \pm 1.5$ & $27 \cdot 0 \pm 3 \cdot 1$ \\
\hline $19-24$ points (cognitive impairment), $n(\%) \ddagger$ & $37(18)$ & $1(3)$ & $38(16)$ \\
\hline GDS, mean (SD) points & $2 \cdot 9 \pm 2 \cdot 6$ & $3 \cdot 2 \pm 4 \cdot 1$ & $3.0 \pm 2.9$ \\
\hline$>5$ points (depression), $n(\%) \ddagger$ & $42(21)$ & $5(13)$ & $47(19)$ \\
\hline
\end{tabular}

GDS, Geriatric Depression Scale; MMSE, Mini-Mental State Examination.

${ }^{*}$ No significant differences between the three treatment groups were observed (one-way ANOVA for continuous variables and $\chi^{2}$ analyses for categorical variables): $P>0.05$

$\dagger$ Values are means and standard deviations.

Values were significantly different from those of the adequate cobalamin group (unpaired $t$-test for continuous variables and $\chi^{2}$ analyses for categorical variables): $\ddagger P<0.05$. 


\section{Blood indices and cognitive function before supplementation}

Mean concentrations for methionine $(25.1 \mu \mathrm{mol} / \mathrm{l})$, choline $(8.0 \mu \mathrm{mol} / \mathrm{l})$, betaine $(32.2 \mu \mathrm{mol} / \mathrm{l})$ and DMG $(3.7 \mu \mathrm{mol} / \mathrm{l})$ in the total screened population ( $n$ 896) did not differ from those concentrations observed in the segment of participants involved in the intervention trial ( $n$ 193; $P>0.05$ for all indices (unpaired $t$-test)). Partial correlation coefficients between the blood indices of the total screened population ( $n$ 896), which were corrected for age and sex, are presented in Table 3. Consistent with the inclusion criteria of mild cobalamin deficiency, participants of the intervention trial had lower cobalamin concentrations and higher tHcy concentrations compared to the total screened population (both $P<0 \cdot 0001$ ).

Partial correlation coefficients, which were corrected for age and education, revealed inverse associations of tHcy concentrations with compound scores for the domains of attention, construction, sensomotor speed and executive function. Methionine concentrations were positively associated with the domain of sensomotor speed, whereas betaine concentrations were positively associated with the domains of construction, sensomotor speed and executive function (Table 3). Further adjustment of our analysis for emotional status and other co- morbidity factors did not affect these associations (data not shown). Moreover, the observed associations did not essentially differ between mildly cobalamindeficient participants and those cobalamin-replete subjects (data not shown).

\section{Changes in blood indices during intervention}

Table 4 presents the concentrations of vitamins and the onecarbon metabolites at baseline and at 24 weeks of supplementation. Concentrations of all metabolites in the placebo group remained stable throughout the study period. The time $\times$ treatment interaction term was significant for cobalamin, tHcy, erythrocyte folate $(P<0.0001$ for these indices) and betaine $(P=0.030)$, which indicates differences in effects between the intervention groups. The effects of treatment did not differ between the intervention groups (no significant interaction terms) for methionine, choline and DMG. Nevertheless, concentrations of methionine and choline increased significantly by 11 and $23 \%$, respectively, after combined supplementation.

\section{Cognitive performance and changes in blood indices}

No differences in cognitive performance between intervention groups were observed at baseline. Since some participants were unable to complete all tests, data of 141,158 and 151 participants were included for analyses on the domains of sensomotor speed, memory and executive function, respectively. There were no significant effects of increases in erythrocyte folate and cobalamin concentrations on cognitive performance, and this had been described elsewhere ${ }^{14}$. Table 5 presents mean changes in cognitive scores according to changes in tHcy, methionine, choline, betaine and DMG, which are categorized into tertiles. In the domain of memory, the time $\times$ tertile category interaction term was only significant for DMG $(P=0 \cdot 04)$, and borderline significant for betaine $(P=0 \cdot 07)$, which indicates differences in memory improvement between the tertiles. Participants with the largest increases in betaine concentrations (third tertile category; change in betaine concentrations $>6.88 \mu \mathrm{mol} / \mathrm{l})$ showed the highest increase in memory performance compared to those in the first and second tertiles. For DMG, participants in the second and third tertiles had a better memory performance compared to those in the first tertile. With respect to the other cognitive domains, no effects within and between tertiles were observed. Further adjustment of our analysis for emotional status and other co-morbidity factors did not affect these associations (data not shown). With respect to emotional status, there were no significant changes in Geriatric Depression Scores between the intervention groups after 24 weeks of supplementation $(P=0 \cdot 32)$.

Table 3. Partial Spearman rank correlation coefficients between one-carbon metabolites and vitamins with one-carbon metabolites, and between one-carbon metabolites with compound cognitive domains in a Dutch elderly population ( $n$ 242) prior to supplementation

\begin{tabular}{|c|c|c|c|c|c|c|}
\hline & \multirow[b]{2}{*}{$n$} & \multicolumn{5}{|c|}{ One-carbon metabolites } \\
\hline & & Choline & Betaine & DMG & tHcy & Methionine \\
\hline \multicolumn{7}{|l|}{ Metabolites } \\
\hline Choline & 896 & & $0.42^{\star \star}$ & $0 \cdot 40^{\star \star}$ & $0 \cdot 14^{\star *}$ & $0 \cdot 24^{\star \star}$ \\
\hline Betaine & 896 & & & $0.35^{\star *}$ & $-0 \cdot 23^{\star *}$ & $0.21^{\star *}$ \\
\hline DMG & 896 & & & & $0 \cdot 24^{\star \star}$ & $0.21^{\star \star}$ \\
\hline tHcy & 896 & & & & & -0.04 \\
\hline Cobalamin & 896 & 0.03 & $0.09^{\star}$ & 0.04 & $-0.27^{\star \star}$ & 0.12 \\
\hline Erythrocyte folate & 896 & $0.09^{\star}$ & $0.24^{\star \star}$ & -0.05 & $-0.41^{\star \star}$ & $0 \cdot 13^{\star \star}$ \\
\hline \multicolumn{7}{|l|}{ Cognition } \\
\hline Attention & 238 & -0.02 & 0.04 & -0.07 & $-0.12 \dagger$ & 0.01 \\
\hline Construction & 236 & 0.06 & $0.19 \dagger \dagger$ & 0.03 & $-0.18 \dagger \dagger$ & 0.01 \\
\hline Sensomotor speed & 222 & -0.07 & $0.14 \uparrow \dagger$ & -0.03 & $-0.26+\dagger$ & 0.16 \\
\hline Memory & 237 & 0.00 & 0.01 & -0.02 & -0.07 & 0.02 \\
\hline Executive function & 233 & 0.00 & $0.13 \dagger \dagger$ & 0.01 & $-0.14 \dagger \dagger$ & 0.10 \\
\hline
\end{tabular}

DMG, dimethylglycine; thcy, total homocysteine.

Partial correlation coefficients corrected for age and sex: ${ }^{\star} P<0.05$; ${ }^{\star \star} P<0.0001$.

Partial correlation coefficients corrected for age and education: $\dagger P<0.10$; $† \dagger<0.05$. 
Table 4. Concentrations of vitamins and one-carbon metabolites at baseline and 24 weeks after supplementation with cobalamin (vitamin $\mathrm{B}_{12}$ ), cobalamin + folic acid or placebo in a Dutch elderly population

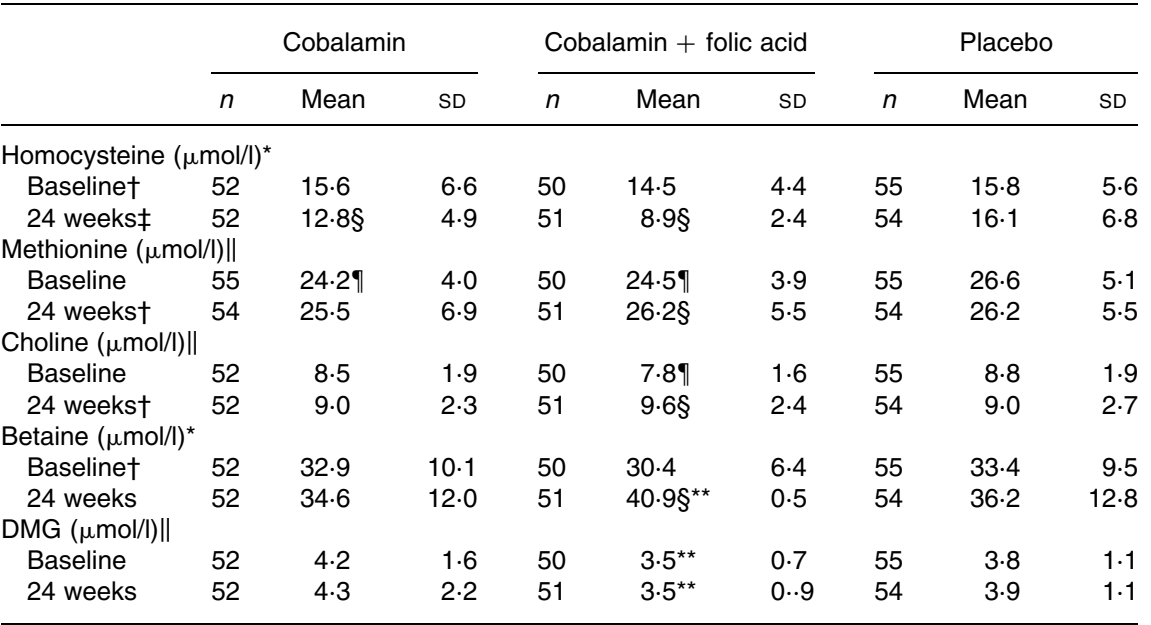

* Treatment effects (changes from baseline within groups) significantly different between the three treatment groups, as indicated by a significant time $\times$ treatment interaction (ANOVA): $P<0.05$.

$\dagger$ No significant differences between the three treatment groups (ANOVA with Tukey post hoc tests): $P>0.05$

¥ Significant differences between the three treatment groups (ANOVA with Tukey post hoc tests): $P<0.05$.

Mean values were significantly different from those of the baseline (ANOVA repeated-measures analysis with LSMEANS): $\$ P<0.05$

$\|$ Treatment effects (changes from baseline within groups) not significantly different between the three treatment groups, as indicated by a non-significant time $\times$ treatment interaction (ANOVA): $P>0.05$.

Mean values were significantly different from those of the placebo (ANOVA with Tukey post hoc tests): $P<0.05$

Mean values were significantly different from those of the cobalamin group (ANOVA with Tukey post hoc tests): ${ }^{\star \star} P<0.05$.

Table 5. Mean cognitive changes in $z$-scores by tertiles in changes of one-carbon metabolites due to cobalamin with or without folic acid supplementation in a Dutch elderly population $(n 195)^{\star}$

\begin{tabular}{|c|c|c|c|c|c|c|c|c|c|c|}
\hline & \multicolumn{2}{|c|}{ tHcy } & \multicolumn{2}{|c|}{ Methionine } & \multicolumn{2}{|c|}{ Choline } & \multicolumn{2}{|c|}{ Betaine } & \multicolumn{2}{|c|}{ DMG } \\
\hline & Mean & $95 \% \mathrm{Cl}$ & Mean & $95 \% \mathrm{Cl}$ & Mean & $95 \% \mathrm{Cl}$ & Mean & $95 \% \mathrm{Cl}$ & Mean & $95 \% \mathrm{Cl}$ \\
\hline \multicolumn{11}{|l|}{ Attention } \\
\hline Tertile 1 & 0.03 & $-0.18,0.25$ & 0.05 & $-0.20,0.29$ & 0.01 & $-0.19,0.21$ & 0.10 & $-0.14,0.34$ & -0.06 & $-0.27,0.14$ \\
\hline Tertile 2 & 0.02 & $-0.26,0.31$ & 0.11 & $-0.14,0.35$ & 0.24 & $-0.03,0.50$ & -0.04 & $-0.27,0.20$ & 0.23 & $-0.04,0.49$ \\
\hline Tertile 3 & 0.10 & $-0.13,0.34$ & 0.00 & $-0.24,0.18$ & -0.08 & $-0.35,0.18$ & 0.08 & $-0.17,0.33$ & 0.01 & $-0.24,0.27$ \\
\hline$P$ trend & 0.8991 & & 0.7358 & & 0.6289 & & 0.7091 & & 0.4811 & \\
\hline \multicolumn{11}{|c|}{ Construction } \\
\hline Tertile 1 & 0.06 & $-0.11,0.24$ & 0.13 & $-0.07,0.32$ & 0.15 & $-0.05,0.36$ & 0.21 & $0.01,0.42$ & 0.03 & $-0.16,0.22$ \\
\hline Tertile 2 & 0.13 & $-0.02,0.27$ & $0 \cdot 12$ & $-0.06,0.30$ & 0.14 & $-0.02,0.31$ & 0.12 & $-0.07,0.31$ & 0.24 & $0.05,0.42$ \\
\hline Tertile 3 & 0.21 & $-0.002,0.44$ & 0.16 & $-0.03,0.35$ & 0.10 & $-0.10,0.29$ & 0.05 & $-0.11,0.21$ & 0.15 & $-0.04,0.34$ \\
\hline$P$ trend & 0.8494 & & 0.1738 & & 0.5745 & & 0.0669 & & 0.0602 & \\
\hline \multicolumn{11}{|c|}{ Sensomotor speed } \\
\hline Tertile 1 & 0.07 & $-0.08,0.22$ & 0.01 & $-0.14,0.17$ & 0.03 & $-0.11,0.16$ & 0.05 & $-0.10,0.20$ & 0.05 & $-0.10,0.20$ \\
\hline Tertile 2 & 0.00 & $-0.12,0.12$ & 0.02 & $-0.11,0.15$ & 0.02 & $-0.12,0.16$ & 0.01 & $-0.12,0.14$ & 0.03 & $-0.08,0.15$ \\
\hline Tertile 3 & -0.03 & $-0.16,0.12$ & 0.01 & $-0.12,0.15$ & 0.00 & $-0.14,0.15$ & -0.02 & $0.15,0.12$ & -0.03 & $-0.18,0.11$ \\
\hline$P$ trend & 0.9569 & & 0.4994 & & 0.7232 & & 0.0857 & & 0.4233 & \\
\hline \multicolumn{11}{|l|}{ Memory } \\
\hline Tertile 1 & 0.25 & $-0.02,0.52$ & 0.28 & $0.20,0.40$ & 0.29 & $0.17,0.40$ & $0 \cdot 25^{\mathrm{a}, \mathrm{b}}$ & $0.13,0.38$ & $0.17^{\mathrm{a}}$ & $0.08,0.26$ \\
\hline Tertile 2 & 0.23 & $0.00,0.45$ & 0.28 & $0.16,0.40$ & 0.30 & $0.21,0.39$ & $0.20^{\mathrm{a}}$ & $0.09,0.31$ & $0.35^{\mathrm{b}}$ & $0.23,0.48$ \\
\hline Tertile 3 & 0.35 & $0.07,0.63$ & 0.28 & $0.14,0.42$ & 0.26 & $0.13,0.39$ & $0.38^{\mathrm{b}}$ & $0.29,0.50$ & $0.33^{\mathrm{b}}$ & $0.21,0.45$ \\
\hline$P$ trend & 0.1287 & & 0.2767 & & 0.3253 & & 0.1000 & & 0.4522 & \\
\hline \multicolumn{11}{|c|}{ Executive function } \\
\hline Tertile 1 & 0.03 & $-0.10,0.16$ & 0.04 & $-0.08,0.15$ & 0.05 & $-0.06,0.15$ & 0.08 & $-0.02,0.19$ & 0.01 & $-0.11,0.13$ \\
\hline Tertile 2 & 0.03 & $-0.06,0.12$ & 0.08 & $0.00,0.17$ & 0.05 & $-0.07,0.17$ & -0.01 & $-0.14,0.11$ & 0.14 & $0.05,0.23$ \\
\hline Tertile 3 & 0.12 & $0.03,0.22$ & 0.06 & $-0.06,0.18$ & 0.08 & $-0.01,0.17$ & 0.10 & $0.00,0.20$ & 0.03 & $-0.08,0.15$ \\
\hline$P$ trend & 0.2966 & & 0.9950 & & 0.2676 & & 0.2518 & & 0.9345 & \\
\hline
\end{tabular}

DMG, dimethylglycine; tHcy, total homocysteine.

${ }^{\mathrm{a}, \mathrm{b}}$ Mean changes in $z$-scores with unlike superscript letters were significantly different $(P<0.05)$.

${ }^{*}$ At baseline, mean compound $z$-scores were essentially 0 (SD 1), as a result of standardizing and combining crude cognitive scores into standardized compound z-scores. Analyses are adjusted for age, education and neuropsychologists. The cut-off points for tertile categories in changes of thcy were -3.95 and $-0.7 \mu$ mol/l; for methionine they were -1.32 and $2.88 \mu \mathrm{mol} / \mathrm{l}$; for choline they were -0.17 and $1.48 \mu \mathrm{mol} / \mathrm{l}$; for betaine they were -1.43 and $6.88 \mu \mathrm{mol} / \mathrm{l}$; and for DMG they were -0.33 and $0.41 \mu \mathrm{mol} / \mathrm{l}$. $P$ values indicate tests for trend across median changes in concentrations for each tertile. Analyses are corrected for age, education and neuropsychologist. 


\section{Discussion}

The present study showed that elevated plasma tHcy was associated with lower performance of attention, construction, sensomotor speed and executive function. In addition, betaine was positively associated with better performance of construction, sensomotor speed and executive function, whereas elevated concentrations of methionine were positively associated with sensomotor speed prior to supplementation. Daily oral supplementation of $1000 \mu \mathrm{g}$ cobalamin with $400 \mu \mathrm{g}$ folic acid for a period of 24 weeks decreased tHcy concentrations and increased betaine concentrations. There was a tendency for participants with the largest increases in betaine concentrations to show the greatest improvement in memory function.

To our knowledge, the current study is the first one that explores associations of cognitive function with choline, betaine and DMG in an elderly population. Previous animal ${ }^{24,25}$ and human $^{8,9,26}$ studies indicate a strong interrelationship between the betaine-homocysteine methyltransferase and methionine synthase pathways. This is reflected in lower hepatic choline concentrations during folate deficiency ${ }^{25,26}$ and vice versa ${ }^{24}$, inverse relations between betaine and homocysteine during folate deficiency ${ }^{8}$, and increased betaine concentrations after folic acid supplementation ${ }^{9}$. The latter findings ${ }^{9}$ are in line with results of the present trial.

Conceivably, diseases associated with high plasma tHcy concentrations may not only be linked to low concentrations of cobalamin and folate, but also with low concentrations of betaine and choline. So far, only one non-placebo-controlled pilot study in eight patients with Alzheimer's disease ${ }^{27}$ have investigated the effect of oral betaine supplementation, and their results were negative. In contrast, the present trial showed that participants with the largest increases in betaine concentrations (third tertile category; change in betaine concentrations $>6.88 \mu \mathrm{mol} / \mathrm{l}$ ) showed the highest increase in memory performance compared to those in the first and second tertile categories. Given the fact that the changes in betaine and homocysteine concentrations were most pronounced in the group supplemented with cobalamin plus folate, and were related to the increase in erythrocyte folate concentrations (Table 3), it is possible that folate supplementation accounted for the observed cognitive changes. However, of the recently reported trials ${ }^{13-15}$, only the FACIT trial has observed a beneficial effect of folate supplementation on memory function ${ }^{15}$. The inconclusive results among the reported trials could possibly be explained by variations in study durations, sample sizes, characteristics of study population and assessment of cognitive function.

The apparent effect of the increase in betaine concentrations on improved memory function may also reflect greater availability of choline metabolites for synthesis of the neurotransmitter acetylcholine and several phospholipids, such as phosphatidylcholine and sphingomyelin ${ }^{28}$. Choline metabolism is closely related to several aspects of the central nervous system function and structure. An adequate supply of choline appears to be essential for fetal cholinergic neuronal development, in particular for brain regions involved in learning and memory processes ${ }^{28}$. Choline is a precursor of brain sphingomyelin, which is a component of white matter myelin ${ }^{7}$. It has been proposed that changes in white matter sphingomyelin or phospholipid content precede clinical deterioration in demyelinating diseases such as multiple sclerosis $^{29}$. There is some evidence that supplementation with cytidinediphospho-choline could protect against and prevent memory impairment in ageing rats $^{30,31}$, and has beneficial effects on memory and behaviour in elderly people with cognitive problems ${ }^{32}$. The present study describes the association of plasma choline with cognitive status, and the absence of associations prior to supplementation is inconsistent with the hypothesis that choline status is related to cognitive impairment. The lack of associations between plasma choline and cognitive function in the present study may reflect the possibility that plasma free choline represents only a minor fraction of the total choline pool ${ }^{7}$, and may be a poor marker of choline status and metabolism in the brain, which has also been previously suggested ${ }^{33}$.

For DMG, participants in the second and third tertile had a better memory performance compared to those in the first tertile. This observation may reflect changes in cognition during altered betaine metabolism because there is a positive relation between the two metabolites at low but not high DMG concentrations $^{8}$. However, the DMG-memory association could be a chance finding. This possibility is strengthened by the observation that DMG did not change during the intervention.

In summary, the present trial is the first to explore associations of cognitive function with choline, betaine and DMG. We observed associations of homocysteine and betaine with cognitive domains prior to B-vitamin supplementation. Furthermore, there was a tendency that participants with the largest increases in betaine concentrations due to combined supplementation with cobalamin plus folic acid showed the greatest improvement in memory performance.

\section{Acknowledgements}

We are indebted to the participants who took part in this study, and to the directors and staff of the care facility homes for their support. We thank OveÅrseth and Randi Mjelde Heimdal for carrying out all biochemical assays at the LOCUS of Homocysteine and Related Vitamins in Bergen, Lisette Verhoeven, Daniëlle van Hout, Rubia Bloo and Liesbeth Joosten of the Medical Psychology department in Nijmegen for the design of the neuropsychological test battery and their assistance in neuropsychological sessions. In addition, we thank the research assistants, MSc students in Human Nutrition and Neuropsychology, and nurses for their assistance in recruitment and blood collections. This research was supported by grant 2100.0067 from ZON-MW, the Hague, The Netherlands; grant 001-2002 from Kellogg's Benelux, Zaventem, Belgium; grant QLK3-CT-2002-01 775 from the Foundation to Promote Research into Functional Cobalamin Deficiency and the European Union BIOMED Demonstration Project; and grant 2004E2 from the Nutricia Health Foundation, Wageningen, The Netherlands.

\section{References}

1. Selhub J, Bagley LC, Miller J \& Rosenberg IH (2000) B vitamins, homocysteine, and neurocognitive function in the elderly. Am J Clin Nutr 71, 614S-620S.

2. Calvaresi E \& Bryan J (2001) B vitamins, cognition, and aging: a review. J Gerontol B Psychol Sci Soc Sci 56, 327-339. 
3. Garcia A \& Zanibbi K (2004) Homocysteine and cognitive function in elderly people. CMAJ 171, 897-904.

4. Malouf M, Grimley EJ \& Areosa SA (2003) Folic acid with or without vitamin B12 for cognition and dementia. Cochrane Database Syst Rev CD004514.

5. Malouf R \& Areosa SA (2003) Vitamin B12 for cognition. Cochrane Database Syst Rev CD004326.

6. Malouf R \& Grimley Evans J (2003) The effect of vitamin B6 on cognition. Cochrane Database Syst Rev CD004393.

7. Zeisel SH (2004) Nutritional importance of choline for brain development. J Am Coll Nutr 23, 621S-626S.

8. Holm PI, Ueland PM, Vollset SE, et al. (2005) Betaine and folate status as cooperative determinants of plasma homocysteine in humans. Arterioscler Thromb Vasc Biol 25, 379-385.

9. Melse-Boonstra A, Holm PI, Ueland PM, Olthof M, Clarke R \& Verhoef P (2005) Betaine concentration as a determinant of fasting total homocysteine concentrations and the effect of folic acid supplementation on betaine concentrations. Am J Clin Nutr 81, 1378-1382.

10. Miller AL (2003) The methionine-homocysteine cycle and its effects on cognitive diseases. Altern Med Rev 8, 7-19.

11. Stabler SP (2000) B12 and nutrition. In Chemistry and Biochemistry of B12, pp. 343-365 [R Banjeree, editor]. New York: Wiley and Sons.

12. Ueland PM, Holm PI \& Hustad S (2005) Betaine: a key modulator of one-carbon metabolism and homocysteine status. Clin Chem Lab Med 43, 1069-1075.

13. McMahon JA, Green TJ, Skeaff CM, Knight RG, Mann JI \& Williams SM (2006) A controlled trial of homocysteine lowering and cognitive performance. $N$ Engl J Med 354, 2764-2772.

14. Eussen SJ, de Groot LC, Joosten LW, et al. (2006) Effect of oral vitamin B-12 with or without folic acid on cognitive function in older people with mild vitamin B-12 deficiency: a randomized, placebo-controlled trial. Am J Clin Nutr 84, 361-370.

15. Durga J, van Boxtel MP, Schouten EG, et al. (2007) Effect of 3 -year folic acid supplementation on cognitive function in older adults in the FACIT trial: a randomised, double blind, controlled trial. Lancet 369, 208-216.

16. Baik HW \& Russell RM (1999) Vitamin B12 deficiency in the elderly. Aпnи Rev Nutr 19, 357-377.

17. Windelberg A, Arseth O, Kvalheim G \& Ueland PM (2005) Automated assay for the determination of methylmalonic acid, total homocysteine, and related amino acids in human serum or plasma by means of methylchloroformate derivatization and gas chromatography-mass spectrometry. Clin Chem 51, 2103-2109.

18. Holm PI, Ueland PM, Kvalheim G \& Lien EA (2003) Determination of choline, betaine, and dimethylglycine in plasma by a high-throughput method based on normal-phase chromatography-tandem mass spectrometry. Clin Chem $\mathbf{4 9}$, 286-294.

19. van Asselt DZ, Pasman JW, van Lier HJ, et al. (2001) Cobalamin supplementation improves cognitive and cerebral function in older, cobalamin-deficient persons. J Gerontol A Biol Sci Med Sci 56, M775-M779.

20. Tombaugh TN \& McIntyre NJ (1992) The mini-mental state examination: a comprehensive review. J Am Geriatr Soc $\mathbf{4 0}$, 922-935.

21. Barnes LL, Wilson RS, Schneider JA, Bienias JL, Evans DA \& Bennett DA (2003) Gender, cognitive decline, and risk of AD in older persons. Neurology 60, 1777-1781.

22. Visser PJ (2006) Role of cognitive testing in disease modifying AD trials. J Nutr Health Aging 10, 131-132.
23. Singer J (1998) Using SASPROCMIXED to fit multilevel models, hierarchical models, and individual growth models. $J$ Educ Behav Stat 24, 323-355.

24. Selhub J, Seyoum E, Pomfret EA \& Zeisel SH (1991) Effects of choline deficiency and methotrexate treatment upon liver folate content and distribution. Cancer Res 51, 16-21.

25. Kim YI, Miller JW, da Costa KA, et al. (1994) Severe folate deficiency causes secondary depletion of choline and phosphocholine in rat liver. $J$ Nutr 124, 2197-2203.

26. Jacob RA, Jenden DJ, Allman-Farinelli MA \& Swendseid ME (1999) Folate nutriture alters choline status of women and men fed low choline diets. $J$ Nutr 129, 712-717.

27. Knopman D \& Patterson M (2001) An open-label, 24-week pilot study of the methyl donor betaine in Alzheimer disease patients. Alzheimer Dis Assoc Disord 15, 162-165.

28. Zeisel SH (2000) Choline: an essential nutrient for humans. Nutrition 16, 669-671.

29. Tartaglia MC, Narayanan S, De Stefano N, et al. (2002) Choline is increased in pre-lesional normal appearing white matter in multiple sclerosis. J Neurol 249, 1382-1390.

30. Teather LA \& Wurtman RJ (2005) Dietary CDP-choline supplementation prevents memory impairment caused by impoverished environmental conditions in rats. Learn Mem 12, $39-43$

31. Teather LA \& Wurtman RJ (2003) Dietary cytidine (5')-diphosphocholine supplementation protects against development of memory deficits in aging rats. Prog Neuropsychopharmacol Biol Psychiatry 27, 711-717.

32. Fioravanti M \& Yanagi M (2005) Cytidinediphosphocholine (CDP-choline) for cognitive and behavioural disturbances associated with chronic cerebral disorders in the elderly. Cochrane Database Syst Rev CD000269.

33. Amenta F, Parnetti L, Gallai V \& Wallin A (2001) Treatment of cognitive dysfunction associated with Alzheimer's disease with cholinergic precursors. Ineffective treatments or inappropriate approaches? Mech Ageing Dev 122, 2025-2040.

34. Folstein MF, Folstein SE \& McHugh PR (1975) 'Mini-mental state'. A practical method for grading the cognitive state of patients for the clinician. J Psychiatr Res 12, 189-198.

35. Houx P (1991) Cognitive Aging and Health-related Factors, pp. 113-121. Maastricht: Maastricht University.

36. Visser RSH (1985) Manual of the Complex Figure Test. Lisse: Swets and Zeitlinger.

37. Saan RJ \& Deelman BG (1986) De nieuwe 15-woordentest $(A$ en B) een handleiding. (New 15-words Test $(A$ and $B)$ a Manual). Lisse: Swets and Zeitlinger.

38. Reitan R (1958) Validity of the Trail Making Test as an indicator of organic brain damage. Percept Mot Skills 8, 271-276.

39. Wechsler D (1987) Wechsler Memory Scale - Revised Manual. San Antonio: Psychological Corporation.

40. Raven J (1965) Guide to Using the Coloured Progressive Matrices. London: HK Lewis.

41. Stroop J (1935) Studies of interference in serial verbal reactions. J Exp Psychol 18, 643-662.

42. Houx PJ, Jolles J \& Vreeling FW (1993) Stroop interference: aging effects assessed with the Stroop Color-Word Test. Exp Aging Res 19, 209-224.

43. Wechsler D (1981) Manual for the Wechsler Adult Intelligence Scale - Revised. New York: Psychological Corporation.

44. Luteijn FvdPF (1983) Handleiding Groninger Intelligentietest (Manual Groningen Intelligence Test). Lisse: Swets and Zeitlinger.

45. Yesavage JA \& Brink TL (1983) Development and validation of a geriatric depression screening scale: a preliminary report. $J$ Psy Res 1, 37-49. 